\title{
SISTEM INFORMASI EVALUASI KARYAWAN BERBASIS WEB PADA PT PRAWEDA CIPTAKARSA INFORMATIKA JAKARTA
}

\author{
Susi Susanti \\ Program Studi Sistem Informasi \\ STMIK Nusa Mandiri \\ www.nusamandiri.ac.id \\ susisr.praweda@gmail.com
}

\begin{abstract}
Abstrak
Proses evaluasi pada PT. Praweda Ciptakrsa Informatika masih bersifat konvensional. Selama ini cara berkompetensi yang ada pada PT. Praweda Ciptakarsa Informatika masih belum sesuai dengan pengharapan karyawan, karena masih adanya penilaian yang tidak transparan yang dilakukan saat penilaian kinerja. Untuk menjawab permasalahan diatas, perusahaan membutuhkan suatu sistem yang dapat menyimpan data dan informasi mengenai parameter evaluasi kinerja, menyimpan hasil evaluasi, serta membantu tim leader dalam melaksanakan proses evaluasi kinerja karyawan. Sistem informasi karyawan dapat menghasil laporan hasil evaluasi karyawan, yang dapat membantu atasan dalam pengambilan penilaian terhadap karyawan yang bersangkutan secara transparan.
\end{abstract}

Kata kunci: Sistem Informasi Evaluasi, Evaluasi Karyawan, Web Base

\begin{abstract}
The evaluation process at PT. Praweda Ciptakrsa Informatika is still conventional. During this time the competency methods in PT. Praweda Ciptakarsa Informatika is still not in line with employee expectations, because there are still non-transparent assessments made during performance appraisals. To answer the above problems, companies need a system that can store data and information about performance evaluation parameters, store evaluation results, and assist team leaders in carrying out employee performance evaluation processes. Employee information systems can produce employee evaluation reports, which can help superiors in making evaluations of the employees concerned transparently.
\end{abstract}

Keywords: Evaluation Information System, Employee Evaluation, Web Base

\section{PENDAHULUAN}

Perusahaan sebagai salah satu organisasi berkaitan erat dengan lingkungan yang ada disekitarnya, baik internal maupun ekternal perusahaan. Semakin pesatnya persaingan di dunia bisnis membuat perusahaan dituntut untuk dapat mempertahankan keberadaannya. Maka dari itu perusahaan perlu mengembangkan kualitas dalam memanfaatkan segala kesempatan dan menghadapi tantangan-tantangan yang ada. Dalam lingkungan internal, karyawan menjadi aset penting dalam menjalankan segala aktifitas yang terjadi di perusahaan. Hal ini membuat perusahaan perlu melakukan pengembangan karyawan yang ada di dalamnya. Karyawan yang berkualitas dan dapat berkembang akan membuat perusahaan semakin berkembang dan berkualitas pula.

PT. Praweda Ciptakarsa Informatika merupakan salah satu perusahaan yang bergerak di bidang teknologi informasi. Dalam mengembangkan perusahaan, kinerja karyawan menjadi aspek yang perlu diperhatikan. Jika kinerja karyawan baik maka akan berpengaruh baik pula bagi perkembangan perusahaan, namun jika kinerja karyawan dibawah standar perusahaan maka perusahaan perlu melakukan pembinaan dan pengembangan terhadap karyawan tersebut. Untuk mengetahui sejauh mana kinerja dari karyawan, maka perusahaan memerlukan suatu sistem yang dapat mengevaluasi kinerja karyawan.

Proses evaluasi pengembangan karyawan PT. Praweda Ciptakarsa Informatika, penilaian tersebut dirasa masih bersifat subjektif (Saefudin \& Wahyuningsih, 2017), turunnya motivasi kerja karyawan, hingga tingginya intensi turnover karyawan (Evita, Muizu, \& Atmojo, 2017), sementara ini masih penilaian evaluasi pengembangan dilakukan oleh pimpinan ditulis pada kertas penilaian kinerja karyawan, kemudian hitungan hasil penilian ditulis pada kertas tersebut, hal ini bisa saja terjadi salah hitung, apa bila lembar penilaian tersebut bisa saja tercecer dan hilang (Natanael \& Mulyono, 2017). 
Evaluasi karyawan belum memiliki skema data untuk menyimpan data pada periode penilaian kinerja sebelumnya. Masih ditemukannya kelemahan (Septiani, Syafi'i, \& Rasyidi, 2015) dalam penyampaian informasi kegiatan pembelajaran dan evaluasi yang terdapat pada perusahaan tersebut. Selama ini proses evaluasi pada PT. Praweda Ciptakrsa Informatika masih bersifat konvensional (Adhar, 2014) Selama ini cara berkompetensi yang ada pada PT. Praweda Ciptakarsa Informatika masih belum sesuai dengan pengharapan karyawan, karena masih adanya penilaian yang kurang objektif (Mahdang, Lamangida, \& Mohi, 2016) yang dilakukan saat penilaian kinerja.

Untuk menjawab permasalahan diatas, perusahaan membutuhkan suatu sistem yang dapat menyimpan data dan informasi mengenai parameter evaluasi kinerja, menyimpan hasil evaluasi, serta membantu tim leader dalam melaksanakan proses evaluasi kinerja karyawan. Dan berdasarkan observasi dan wawancara dilapangan maka diperlukan aplikasi evaluasi kinerja karyawan.

Tujuan penelitian ini untuk mewujudkan suatu program apalikasi sistem informasi evaluasi berbasis web guna membantu dalam pemahaman materi yang diberikan oleh perusahaan itu sendiri. Sistem informasi evaluasi karyawan berbasis web ini dirancang untuk mengelola karyawan agar dapat berprestasi dan berkompentensi dengan baik dan transparan. Sistem informasi evaluasi karyawan yang akan membantu tim leader serta karyawan dalam melakukan proses evaluasi dan melihat kinerja karyawan dari berbagai periode. Selain itu sistem informasi dapat memberikan sumber data yang dapat digunakan untuk evaluasi kinerja

\section{METODE PENELITIAN}

\section{Jenis Penelitian}

Penelitian ini menggunakan pendekatan penelitian rancangan eksperimental (experimental design) Sistem informasi

\section{Waktu dan Tempat Penelitian}

Tempat penelitian pada PT. Praweda Ciptakarsa Informatika yang beralamat di Rukan Permata Senayan Blok A 07 Lt. 04 Grogol Utara, Kebayoran Lama, Jakarta Selatan.

\section{Target/Subjek Penelitian}

Target/subjek penelitian pada Aplikasi yang berfokus pada metode kegiatan evaluasi, serta materi yang harus dipahami karyawan.
Aplikasi hanya membuat proses kegiatan menjadi lebih mudah dari segi efisiensi waktu.

Data, Intrumen, dan Teknik Pengumpulan Data

Tahap pengumpulan data adalah pengumpulan data dari tempat penelitian sesuai yang dibutuhkan dalam membangun aplikasi pengkajian.

a. Observasi

Proses Observasi dilakukan dengan mengamati secara langsung proses evaluasi kerja karayawan di cabang PT. Praweda Ciptakarsa Informatika yang beralamat di Rukan Permata Senayan Blok A 07 Lt. 04 Grogol Utara, Kebayoran Lama, Jakarta Selatan, telepon 021-5328575. Dengan mengamati semua proses yang berjalan.

b. Wawancara

Wawancara adalah pengumpulan data dengan cara tanya jawab kepada Bapak Suhud Arifin, selaku Tim Leader dari Divisi terkait yang dilakukan langsung di PT. Praweda Ciptakarsa Informatika.

c. Studi Pustaka

Pengumpulan data yang bersumber dari bebagai buku yang menjadi referensi dan pencarian dengan media internet untuk memperoleh data-data tambahan dalam rangka melengkapi penulisan penelitian. Studi literatur adalah pengumpulan data melalui buku-buku, jurnal dan bacaan - bacaan yang ada kaitannya dengan judul penelitian.

\section{Teknik Analisis Sistem Informasi}

Tahap yang dilakukan untuk pembuatan aplikasi ini adalah menggunakan metode waterfall. Dimana tahap demi tahap proses yang dilalui harus menunggu selesainya tahap sebelumnya dan berjalan berurutan. Adapun penjelasannya adalah sebagai berikut:

a. Analisa Kebutuhan Sistem

Tahap analisa kebutuhan sistem mempelajari proses yang berlangsung antar muka, yaitu admin dapat melihat seluruh data yang ada pada aplikasi tersebut dan dapat melakukan edit serta input seperti edit materi, edit soal evaluasi, edit id user dan cetak laporan nilai. Sedangkan untuk user atau karyawan yang menjadi peserta evaluasi dapat melihat data user itu sendiri, materi, data tugas evaluasi, data nilai dan data pribadi.

\section{b. Design}

Pada tahap ini, penulis mendesain sistem dengan hubungan antar entitas yang ada dalam sistem dijabarkan dalam software arsitektur menggunanakan UML (use case diagram, activity 
diagram, squence diagram, class diagram, component diagram dan deployment diagram) sedangkan desain database menggunakan ERD (Entity Relationship Diagram) dan LRS (Logical Record Structure). Adapun untuk merancang user interface meggunakan CodeIgniter dengan tampilan sederhana agar mudah digunakan oleh pengguna.

c. Code Generation

Pada Penelitian ini, bahasa pemograman yang akan digunakan adalah PHP dan CodeIgnter dengan teknik pemrograman 00P (Object Oriented Programming) serta MySQL sebagai software untuk membangun database-nya.

d. Testing

Dalam penelitian ini penggunakan metode pengujian yang digunakan yaitu black box testing, pengujian ini akan dilakukan meliputi halaman login, registrasi, materi yang diberikan perusahaan dan form evaluasi. Jika hasil pengujian sesuai dengan yang diharapkan maka dapat digunakan.

e. Support

Sistem yang telah diuji kemudian diserahkan ke pengguna untuk dioperasikan sesuai kebutuhanya. Tahapan perawatan dibutuhkan dalam masa itu dengan dilakukan pengecekan kesalahan operasionalnya.

\section{HASIL PENELITIAN DAN PEMBAHASAN}

\section{A. Analisis Kebutuhan Softrware}

Berikut ini spesifikasi kebutuhan (system requirement) dari sistem informasi evaluasi pegawai.

\section{Halaman Tim Leader}

A1. Tim Leader dapat melakukan login kedalam sistem

A2. Tim Leader dapat menegelola data pegawai

A3. Tim Leader dapat mengelola data pengajar

A4. Tim Leader dapat mengelola data tugas atau evAluasi

A5. Tim Leader dapat mengelola data materi

A6. Tim Leader dapat mengelola mata pelajarAn departemen

A7. Tim Leader dapat mengelola laporan Evaluasi

\section{Halaman Pegawai}

B1. Pegawai harus melakukan register

B2. Pegawai harus melakukan login

B3. Pegawai dapat melihat dan membuat pesan

B4. Pegawai dapat mengelola profil

B6. Pegawai dapat melihat jadwal kegiatan

B7. Pegawai dapat mengerjakan tugas atau evaluasi

\section{B. Desain}

1. Desain Sistem

a. Desain Sistem Menggunakan Use Case Diagram

1) Use Case Diagram Tim Leader

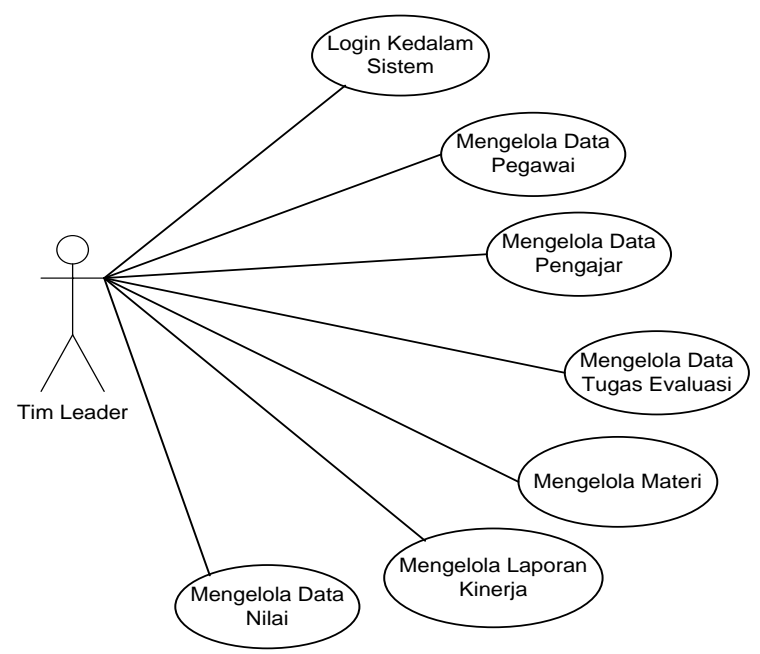

Gambar 1. Use Case Diagram Tim Leader

2) Use Case Diagram Pegawai

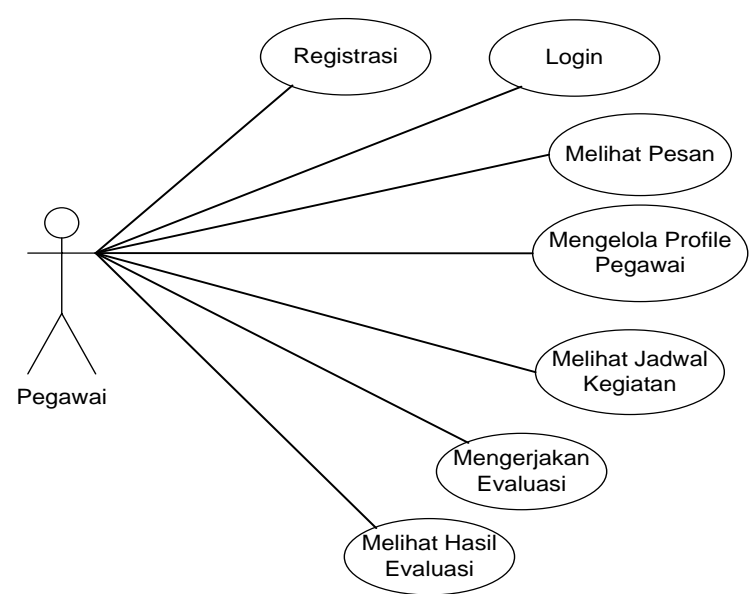

Gambar 2. Use Case Diagram Pegawai

a) Deskripsi Use case Mengerjakan Evaluasi

Tabel 1. Deskripsi Use case Mengerjakan Evaluasi

\begin{tabular}{ll}
\hline Use case & Mengerjakan Evaluasi \\
\hline Requirements & $\begin{array}{l}\text { Pegawai sudah terdaftar sebagai } \\
\text { peserta. }\end{array}$ \\
Poal & $\begin{array}{l}\text { Pegawai dapat mengerjakan soal- } \\
\text { soal evaluasi yang diberikan dengan } \\
\text { benar. }\end{array}$ \\
Pre -conditions & $\begin{array}{l}\text { Pegawai sudah login } \\
\text { Post -conditions }\end{array}$ \\
$\begin{array}{l}\text { Jika valid makan masuk kedalam } \\
\text { ruang evaluasi }\end{array}$ \\
Failed end condition & $\begin{array}{l}\text { Gagal masuk kedalam ruang evaluasi } \\
\text { Primary Actors }\end{array}$ \\
Main flow / Basic path & $\begin{array}{l}\text { Pegai Pegawai membuka ruang evaluasi } \\
\text { 2. Membukan menu tugas dan } \\
\text { melihat list tugas yang tersedia }\end{array}$ \\
\hline
\end{tabular}




\begin{tabular}{ll}
\hline & \multicolumn{2}{l}{ 3. Membuka link tugas yang tersedia } \\
& 4. Mulai mengerjakan soal dan \\
Invariant & menjawab soal evaluasi \\
\hline
\end{tabular}

b. Desain Sistem Menggunakan Activity Diagram

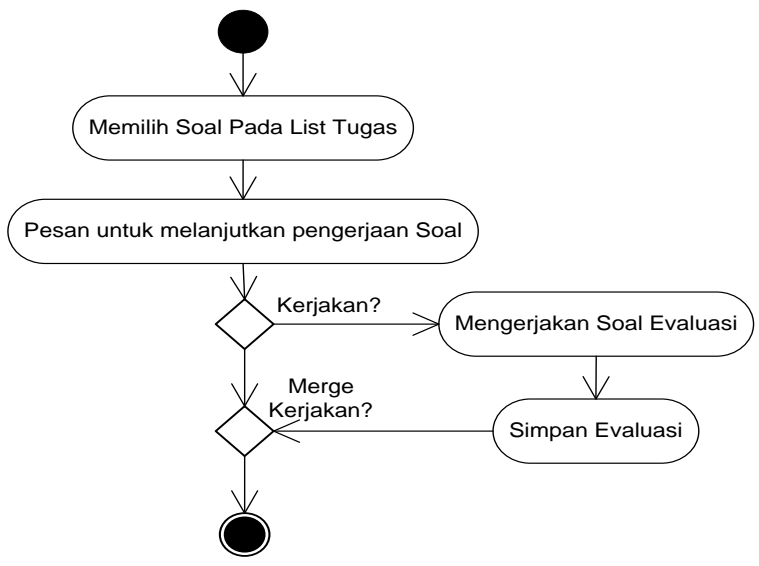

Gambar 3. Use Case Diagram Pegawai

c. Desain Sistem Menggunakan Class Diagram

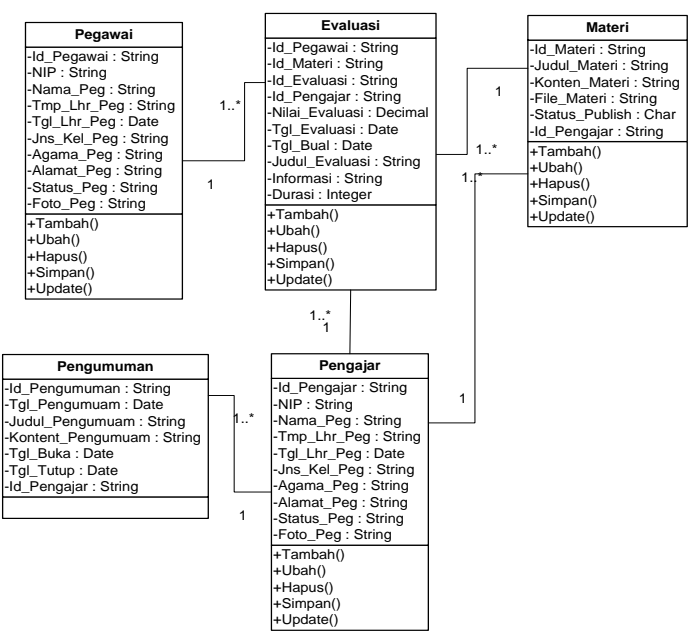

Gambar 4. Class Diagram Sistem Informasi Evaluasi

d. Desain Sistem Menggunakan Sequence Diagram

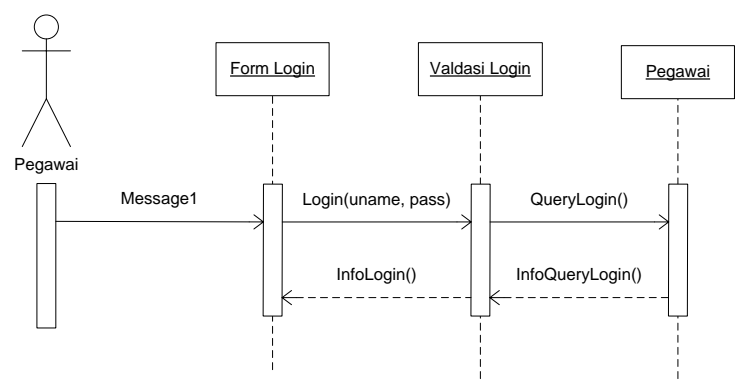

Gambar 5. Sequence Diagram Sistem Informasi Evaluasi

\section{Desain Database}

Rancangan Diagram Data Model Sistem Informasi Evaluasi akan digunakan sebagai database sistem informasi evaluasi dan table-tabel yang akan digunakan pada sistem informasi evaluasi ini.

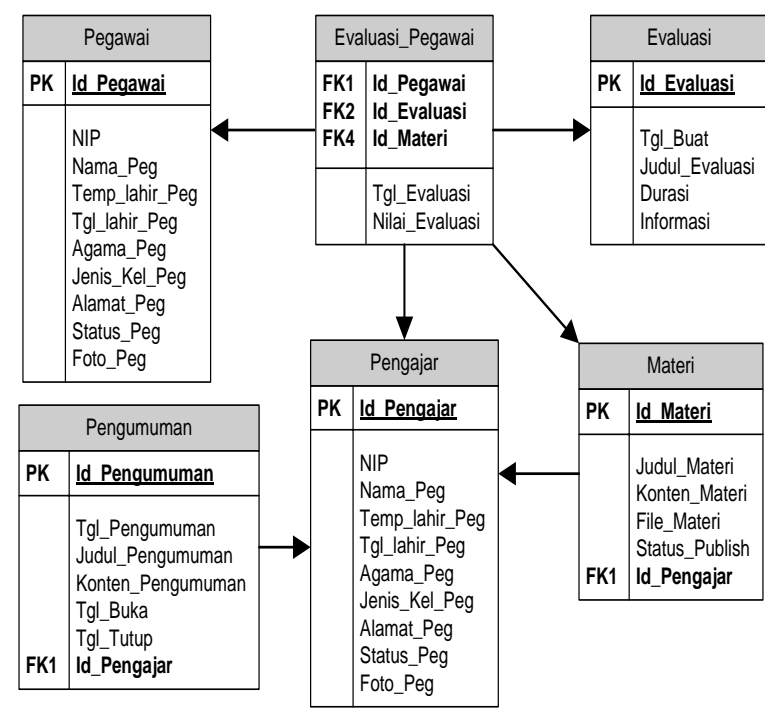

Gambar 6. Diagram Data Model Sistem Informasi Evaluasi

\section{Desain User Interface}

a. Rancangan Halaman Login

Rancangan halaman login ini digunakan untuk para pegawai yang menjadi peserta evaluasi dapat masuk kedalam sistem informasi evaluasi.

Berikut adalah tampilan halaman karyawan saat akan login, masukan username dan password klik login.

Evaluasi PT. PRAWEDA CIPTAKARSA INFORMATIKA

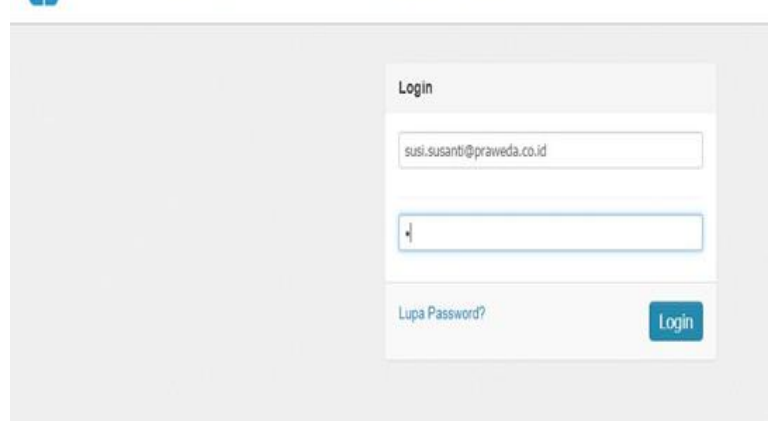

Gambar 7. Halaman Login Evaluasi Pegawai

b. Rancangan Halaman Tugas Pegawai

Rancangan Halaman Tugas Pegawai digunakan untuk supaya pegawai yang sudah masuk kedalam sistem informasi evaluasi dapat memilih tugas apa yang harus dikerjakan saat ini. 


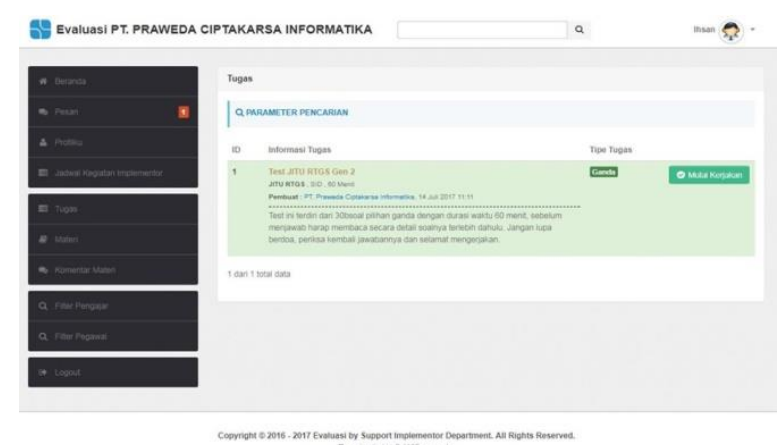

Gambar 8. Tampilan Halaman Tugas Pegawai

c. Rancangan Halaman Evaluasi Pegawai

Rancangan Halaman Evaluasi Pegawai digunakan pegawai untuk melakukan evaluasi yang dilaksanakannya

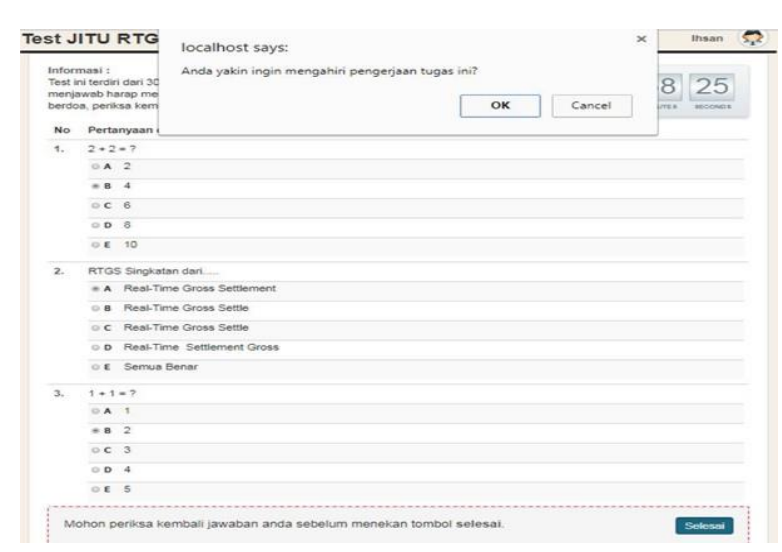

Gambar 9. Halaman Pada Saat Melakukan Evaluasi

\section{Code}

Pada pembahasan ini penulis menggunakan web framework CodeIgniter, dengan teknik pemrograman objek oriented programming (OOP). Bahasa script programming yang digunakan yaitu PHP.

\section{Pengujian (Testing)}

Penelitian ini penggunakan metode pengujian yang digunakan yaitu black box testing.

a. Pengujian Form Login

Tabel 2. Hasil Pengujian Black Box Testing Form

\begin{tabular}{llllll}
\multicolumn{5}{c}{ Login User } \\
\hline $\mathrm{N}$ & Skenario & Test case & Hasil & Hasil & kesim \\
o & pengujian & & $\begin{array}{l}\text { yang } \\
\text { diharap } \\
\text { kan }\end{array}$ & $\begin{array}{l}\text { peng } \\
\text { ujian }\end{array}$ & pulan \\
& & & Sistem & Sesua & valid \\
& & & akan & i & \\
\hline 1 & Mengoson & username : & menola & hara & \\
& gkan & (kosong) & kassword : & pan & \\
& semua & Pagin & & \\
& isian data & (kosong) & dan & & \\
& login, lalu & & menam & & \\
& langsung & & & &
\end{tabular}

\begin{tabular}{|c|c|c|c|c|c|}
\hline & $\begin{array}{l}\text { tombol } \\
\text { 'Login'. }\end{array}$ & & $\begin{array}{l}\text { pilkan } \\
\text { pesan } \\
\text { "userna } \\
\text { me } \\
\text { (Email) } \\
\text { dibuthk } \\
\text { an" }\end{array}$ & & \\
\hline 2 & $\begin{array}{l}\text { Hanya } \\
\text { mengisi } \\
\text { data nama } \\
\text { admin dan } \\
\text { mengoson } \\
\text { gkan data } \\
\text { kata sandi, } \\
\text { lalu } \\
\text { langsung } \\
\text { mengklik } \\
\text { tombol } \\
\text { 'Login'. }\end{array}$ & $\begin{array}{l}\text { username : } \\
\text { (susi.susanti@ } \\
\text { praweda.co.id) } \\
\text { Password: } \\
\text { (kosong) }\end{array}$ & $\begin{array}{l}\text { Sistem } \\
\text { akan } \\
\text { menola } \\
\text { k akses } \\
\text { login } \\
\text { dan } \\
\text { menam } \\
\text { pilkan } \\
\text { pesan } \\
\text { "Userna } \\
\text { me } \\
\text { (Email) } \\
\text { dibutuh } \\
\text { kan" }\end{array}$ & $\begin{array}{l}\text { Sesua } \\
\mathrm{i} \\
\text { hara } \\
\text { pan }\end{array}$ & valid \\
\hline 3 & $\begin{array}{l}\text { Hanya } \\
\text { mengisi } \\
\text { data kata } \\
\text { sandi dan } \\
\text { mengoson } \\
\text { gkan data } \\
\text { nama } \\
\text { admin, } \\
\text { lalu } \\
\text { langsung } \\
\text { mengklik } \\
\text { tombol } \\
\text { 'Login'. }\end{array}$ & $\begin{array}{l}\text { username : } \\
\text { (kosong) } \\
\text { Password: (1) }\end{array}$ & $\begin{array}{l}\text { Sistem } \\
\text { akan } \\
\text { menola } \\
\text { k akses } \\
\text { login } \\
\text { dan } \\
\text { menam } \\
\text { pilkan } \\
\text { pesan } \\
\text { "Userna } \\
\text { me } \\
\text { (Email) } \\
\text { dibutuh } \\
\text { kan" }\end{array}$ & $\begin{array}{l}\text { Sesua } \\
\mathrm{i} \\
\text { hara } \\
\text { pan }\end{array}$ & valid \\
\hline 4 & $\begin{array}{l}\text { Menginpu } \\
\text { tkan } \\
\text { dengan } \\
\text { kondisi } \\
\text { salah satu } \\
\text { data } \\
\text { benar dan } \\
\text { satu lagi } \\
\text { salah, lalu } \\
\text { langsung } \\
\text { mengklik } \\
\text { tombol } \\
\text { 'Login'. }\end{array}$ & $\begin{array}{l}\text { username : } \\
\text { (susi.susanti@ } \\
\text { praweda.co.id) } \\
\text { Password: (1) }\end{array}$ & $\begin{array}{l}\text { Sistem } \\
\text { meneri } \\
\text { ma } \\
\text { akses } \\
\text { login } \\
\text { dan } \\
\text { kemudi } \\
\text { an } \\
\text { langsun } \\
\text { g } \\
\text { menam } \\
\text { pilkan } \\
\text { berand } \\
\text { a } \\
\text { Pegawa } \\
\text { i. }\end{array}$ & $\begin{array}{l}\text { Sesua } \\
\mathrm{i} \\
\text { hara } \\
\text { pan }\end{array}$ & valid \\
\hline
\end{tabular}

\section{E. Support}

Tahapan support diperlukan untuk mendukung sistem penerimaan pegawai berbasis web pada PT. Ugasan Berkat Jaya. Agar sistem dapat dibangun dan terus berjalan dengan baik melalui dukungan hardware dan software yang sesuai dengan kebutuhan sistem.

\section{Publikasi Web}

Untuk website Sistem Informasi Evaluasi Karyawan pada PT. Praweda Ciptakrsa Informatika ini tidak dipublikasikan, karena sistem informasi ini masih terbatas, hanya intranet saja.

2. Spesifikasi Hardware dan Software 
Pada pembuatan aplikasi ini dibutuhkan dua perangkat, yaitu perangkat keras (hardware) dan perangkat lunak (software) dengan spesifikasi sebagai berikut:

Tabel 1. Spesifikasi Hardware dan Software

\begin{tabular}{lll}
\hline \multicolumn{1}{c}{ No. } & \multicolumn{1}{c}{ Kebutuhan } & \multicolumn{1}{c}{ Keterangan } \\
\hline 1 & Sistem Operasi & Windows XP atau di atasnya \\
2 & Processor & LGA 3.0 Ghz \\
3 & RAM & 512 MB atau di atasnya \\
4 & Harddisk & 80 GB atau di atasnya \\
5 & CD-ROM & 52x \\
6 & Monitor & SVGA 14" \\
7 & Key Board & 107 Key \\
8 & Printer & Deskjet atau di atasnya \\
9 & Mouse & Standard Mouse \\
10 & Browser & Mozilla Firefox, Google Chrome, \\
& & Internet Explorer \\
11 & Software & PHP, CodeIgniter, MySql \\
\hline
\end{tabular}

\section{SIMPULAN DAN SARAN}

\section{Simpulan}

Sistem informasi evaluasi karyawan yang dibuat dapat membantu dalam kegiatan evaluasi kinerja karyawan dan dapat digunakan sebagai indikator untuk meningkatkan kualitas karyawan dimasa yang akan datang dapat dijadikan solusi alternatif untuk membantu dalam proses evaluasi karyawan. Sistem informasi karyawan dapat menghasil laporan hasil evaluasi karyawan, yang dapat membantu atasan dalam pengambilan penilaian terhadap karyawan yang bersangkutan secara transparan.

\section{Saran}

Sistem yang dibangun masih memiliki beberapa kekurangan dan keterbatasan, oleh sebab itu ada beberapa hal yang perlu dikembangkan selanjutnya agar menjadi lebih baik, antara lain: Harus adanya perluasan lingkup materi yang diberikan, serta ruang lingkup pengujian tidak hanya pada satu divisi saja, tetapi semua divisi dalam perusahaan tersebut. Sistem yang dibangun dikembangkan dapat berupa web berbasis internet, bukan intranet saja, agar cakupan untuk mengkasenya lebih luas dan mudah, tidak harus dilingkungan kantor saja tetapi dapat diakses dimana saja dan kapan saja. Update merupakan hal penting dalam suatu website, sehingga informasi yang disampaikan dapat terus disesuaikan dengan perkembangan perusahaan.

\section{DAFTAR REFERENSI}

Adhar, D. (2014). Sistem Pendukung Keputusan Pengangkatan Jabatan Karyawan pada PT.Ayn dengan Metode Profile Matching. JATISI (Jurnal Teknik Informatika Dan Sistem Informasi),

1(1), 16-29.
https://doi.org/10.35957/JATISI.V1I1.18

Evita, S. N., Muizu, W. O. Z., \& Atmojo, R. T. W. (2017). PENILAIAN KINERJA KARYAWAN DENGAN

MENGGUNAKANMETODEBEHAVIORALLY

ANCHOR RATING SCALE DAN

MANAGEMENT BY OBJECTIVES (STUDI

KASUS PADA PT QWORDS COMPANY

INTERNATIONAL. Pekbis Jurna, 9(1), 18-32.

Retrieved from

https://ejournal.unri.ac.id/index.php/JPEB/ article/view/4051

Mahdang, A., Lamangida, T., \& Mohi, W. K. (2016). Analisis Pelaksanaan Penilaian Kinerja Pegawai Negeri Sipil di Lingkungan Sekretariat Dewan Provinsi Gorontalo. Publik (Jurnal Ilmu Administrasi), 5(1), 1-9. https://doi.org/10.31314/PJIA.5.1.1-9.2016

Natanael, B., \& Mulyono, H. (2017). Analisis Dan Perancangan Sistem Informasi Penilaian Kinerja Karyawan Pada PT. BPR Universal Sentosa. Informasi, Jurnal Manajemen Sistem, 2(1), 295-302. Retrieved from http://ejournal.stikom-

db.ac.id/index.php/manajemensisteminform asi/article/view/440

Saefudin, S., \& Wahyuningsih, S. (2017). Sistem Pendukung Keputusan Untuk Penilaian Kinerja Pegawai Menggunakan Metode Analytical Hierarchy Process (Ahp) Pada RSUD Serang. JSil (Jurnal Sistem Informasi), 1(0). https://doi.org/10.30656/JSII.V1I0.78

Septiani, A. H., Syafi'i, A., \& Rasyidi, A. (2015). PENERAPAN AUDIT OPERASIONAL ATAS MANAJEMEN FUNGSI SDM UNTUK MENILAI KINERJA KARYAWAN PADA PT.PIONEER FLOUR MILL INDUSTRIES SIDOARJO. EQUITY, 1(2), 32-41. Retrieved from http://fe.ubhara.ac.id/ojs/index.php/equity/ article/view/57 